\title{
Reduction of opioid intake after cooled radiofrequency denervation for sacroiliac joint pain: a retrospective evaluation up to 1 year
}

\author{
Andrea Tinnirello \\ Anesthesiology and Pain Management Unit, Azienda Socio Sanitaria Territoriale della Franciacorta, Brescia, Italy
}

Received June 27, 2019

Revised October 3, 2019

Accepted October 12, 2019

\section{Correspondence}

Andrea Tinnirello

Anesthesiology and Pain Management Unit, Azienda Socio Sanitaria Territoriale della Franciacorta, Via Giovanni XXIII, 2, Brescia 25031, Italy

Tel: +39-3392599568

Fax: +39-0307102793

E-mail: andrea.tinnirello@asst-franciacorta.it

Previous presentation at conferences: The 16th Annual Pain Medicine Meeting of the American Society of Regional Anesthesia (ASRA), 16-18th Nov. 2017, Orlando, FL, USA.
Background: Opioids can present intolerable adverse side-effects to patients who use these analgesics to mitigate chronic pain. In this retrospective analysis, cooled radiofrequency (CRF) denervation was evaluated to provide pain and disability relief and reduce opioid use in patients with sacroiliac joint (SIJ) derived low back pain (LBP).

Methods: Twenty-seven patients with pain from SIJ refractory to conservative treatments, and taking opioids chronically (> $3 \mathrm{mo}$ ), were included. Numeric rating scale (NRS) and Oswestry disability index (ODI) scores were collected at 1, 6, and 12 months post-procedure. Opioid use between baseline and each follow-up visit was compared for the entire group and for those who experienced successful (pain reduction $\geq 50 \%$ of baseline value) or unsuccessful CRF denervation.

Results: Severe initial mean pain (NRS score: $7.7 \pm 1.0)$ and disability (ODI score: $50.1 \pm 9.0$ ), and median opioid use (morphine equivalent daily dose: $40 \pm 37 \mathrm{mg}$ ) were significantly reduced up to 12 months post-intervention. CRF denervation was successful in $44.4 \%$ of the patients at 12 months. Regardless of procedure success, patients demonstrated similar opioid reductions and changes in opioid use at 12 months. Two patients (7.4\%) experienced neuritis following CRF denervation. Conclusions: CRF denervation of the SIJ can safely elicit pain and disability relief, and reduce opioid use, regardless of intervention success. Future studies may support CRF denervation as a dependable therapy to alleviate opioid use in patients with SIJ-derived LBP and show that opioid use measurements can be a surrogate indicator of pain.

Key Words: Analgesics, Opioid; Chronic Pain; Conservative Treatment; Denervation; Low Back Pain; Opioid-Related Disorders; Retrospective Studies; Rhizotomy; Sacroiliac Joint.

\section{INTRODUCTION}

The sacroiliac joint (SIJ) is a common origin of chronic low back pain (LBP) [1,2]. To combat this ailment, patients may engage in conservative therapies, which are non-invasive, but have limited effectiveness. Indeed, the utility of intraarticular joint steroid (IAS) injections or prolotherapy is equivocal [3-5], nonsteroidal anti-inflammatory drugs (NSAIDs) have short-term effectiveness but present adverse effects [6], while in patients with chronic non-specific LBP, the McKenzie physical therapy method was just slightly more effective than a placebo for pain [7]. Surgical fusion is an invasive intervention that may or may not resolve patients SIJ-derived LBP [8]. In contrast to these (a) This is an open-access article distributed under the terms of the Creative Commons Attribution Non-Commercial License (http://creativecommons.org/licenses/by-nc/4.0/), which permits unrestricted non-commercial use, distribution, and reproduction in any medium, provided the original work is properly cited.

(c) The Korean Pain Society, 2020
Author contributions: Andrea Tinnirello: Writing/manuscript preparation. 
approaches, patients may use opioids on a daily basis to facilitate sustained analgesia. However, this strategy can be limited by gradual insensitivity to initial consumption, resulting in dependence as a consequence of progressively higher doses required to provide analgesia [9].

The United States' (US) National Institute on Drug Abuse has summarized the gravity of the ongoing opioid crisis [10], which was born from widespread use of opioids initiated in the 1990s to ease chronic pain [11,12]. Overdosing on opioids is responsible for nearly 100 deaths daily in the US [13]. The US Centers for Disease Control and Prevention estimates prescription opioid misuse in the US costs $\$ 78.5$ billion annually, including the costs of healthcare, lost productivity, addiction treatment, and criminal justice involvement [14]. The opioid crisis is defined by 1) up to onethird of patients prescribed opioids for chronic pain misuse them [15], 2) approximately $10 \%$ of those prescribed opioids develop an opioid misuse disorder [16-18], and 3) approximately $5 \%$ of those who misuse prescription opioids use heroin instead [16-18]. Whereas use of opioids for chronic pain can promote collateral morbidities, and on occasion, mortality, and the traditional non-pharmacological therapies outlined above have limited effectiveness and associated complications, it is clinically imperative that a different treatment be made available for chronic LBP that is different from these interventions.

Cooled radiofrequency (CRF) denervation of nociceptive nerves can be an effective means by which patients can enjoy relief of their SIJ-derived LBP and enhanced quality of life [19-24]. In particular, our previous retrospective observational study illustrated that CRF denervation affords greater analgesia and function than its counterpart conventional $\mathrm{RF}$ technique up to 12 months post-intervention [24]. Other examinations have shown that dissipation in opioid use can accompany CRF denervation-facilitated pain relief $[19,20,22]$, and included a case report [19], 3-, 4-month follow-up [20], and follow-up periods of 6-12 months and more than 12 months [22]. While the latter outcomes especially can help to inform healthcare workers of the generalized durability of CRF for treating SIJ-derived LBP [22], the findings may be subject to under- and/ or overestimations, given that such relatively wide followup time-frames can lend themselves to skewed results.

Thus, in addition to another report that retrospectively evaluated the relationship between CRF denervation and opioid use specifically at 12 months [23], here we report the results of our retrospective examination aimed at determining the influence of CRF denervation on opioid use at 1 , 6, and 12 months following CRF treatment for SIJ-derived LBP.

\section{MATERIALS AND METHODS}

This was a retrospective analysis of patients treated with CRF denervation for SIJ-derived LBP from January 2013 to May 2016. The study was approved by the Ethical Committee of Azienda Socio Sanitaria Territoriale della Franciacorta (IRB No. NP 2306; Comitato Etico Provinciale, Brescia, Italy), and all patients were provided written informed consent to use their outcomes in a report. This study was conducted in an Italian National Health Service Public Hospital.

\section{Patients}

The patients considered for inclusion in this study were consecutively admitted to the pain management unit of Azienda Socio Sanitaria Territoriale della Franciacorta for chronic LBP lasting for at least 6 months. Only patients taking opioids at the time of the CRF denervation procedure were included in our analysis. As such, while 31 patients received CRF denervation, 27 of these were included in the analyses of this study, because the remaining four were not using opioids at the time of CRF treatment. Following denervation, patients were instructed to reduce opioid medication intake according to their perceived health status (dosage reduction was monitored by patients' general practitioners in order to prevent adverse effects from sudden withdrawal).

\section{Diagnosis of SIJ-derived LBP}

The diagnosis of SIJ-derived LBP was made as follows: 1) the patient had pain in the buttock or low back below L5, with radiation to the groin and/or thigh $[25,26], 2)$ positivity on at least three out of six provocation tests for SIJ pain, specifically a thigh thrust test, distraction test, a Gaenslen's test on both sides, a compression test, and sacral thrust test [26], and 3) pain relieved by joint injection with an anesthetic [27]. An intra-articular test block by $0.75 \%$ ropivacaine $(2 \mathrm{~mL}$ ) was performed under fluoroscopic guidance using a $22-\mathrm{G}, 100 \mathrm{~mm}$ spinal needle positioned in the lower third of the joint [24]. The intra-articular spread of injected contrast medium was observed to confirm correct positioning of the needle. Patients who experienced pain relief of $50 \%$ or greater within five hours of the test block were diagnosed with SIJ pain.

Patients excluded from the study included those with 1) pain radiating below the knee or above L5, 2) other possible sources of LBP (determined by means of physical exam, medical history, and magnetic resonance imaging/ computed tomography/X-ray, as well as rheumatology screening, as required), including, but not limited to, bone 
fractures, the hip joint, symptomatic spondylolisthesis, tumor, and other regional soft tissue structures [28]. Also excluded from SIJ denervation were those who were 1) younger than age 18 years old, 2) pregnant, 3) mentally handicapped, or had 1) a blood coagulation disorder, 2) an infection at the intended site of the intervention, or 3) an allergy to local anesthetics that were used.

Previous conservative therapies for patients diagnosed with SIJ-derived pain included multiple (up to three times) injections ( $\mathrm{n}=2.2 \pm 0.5$ per patient; mean \pm standard deviation [SD]) in the SIJ with a local anesthetic (ropivacaine, $2 \mathrm{mg} /$ injection), a steroid (methylprednisolone, $40 \mathrm{mg} /$ injection), and regularly-prescribed opioids and NSAIDs. Patients who failed conservative treatments were scheduled for CRF denervation.

\section{CRF denervation}

Each prone-positioned, lightly sedated patient had a pillow placed beneath their abdomen, and the skin at the intervention site was numbed with $2 \%$ lidocaine. The S1, S2, and S3 foramina were identified by fluoroscopic guidance on the treatment side of the spine, and a 17-G introducer needle was inserted lateral to each target foramen until contact with the bone was achieved. Sensory stimulation in the SIJ at $50 \mathrm{~Hz}$ was performed to elicit paresthesia under $0.8 \mathrm{~V}$, while to verify no motor recruitment in the ipsilateral lower extremity, motor stimulation was conducted at $2 \mathrm{~Hz}$ and at up to $1.5 \mathrm{~V}$. Denervation by CRF (Avanos Medical Inc., Alpharetta, GA) was performed for 150 seconds at $60^{\circ} \mathrm{C}$, with three lesions created at $\mathrm{Sl}$ and S2, and two at S3 [24]. The needle was positioned between the junction of the sacral ala and the S1 superior articular process to lesion the L5 dorsal ramus [24,29-31]. After each procedure, the patient was observed for at least four hours before being discharged.

\section{Outcomes}

The primary outcome was the reduction in opioid consumption after CRF. Secondary outcomes were the reductions in pain and disability. Primary and secondary outcomes were measured at 1,6 , and 12 months after the CRF procedure. Baseline values were recorded on the day of the CRF procedure.

Opioid consumption, measured as the oral morphine equivalent daily dose (MEDD) in $\mathrm{mg}$, was captured for each patient in the study. The MEDD was calculated using the calculator provided in the Agency Medical Directors' Group 2015 Guidelines [32].

The numeric rating scale (NRS) was used to assess pain $(0=$ 'no pain' and $10=$ 'worst pain') [33]. The CRF denerva- tion was considered a 'treatment success' if the patientreported a follow-up NRS score relative to the respective baseline score that was reduced by $\geq 50 \%$ [34]. The Oswestry disability index (ODI) was used to assess the extent of disability associated with SIJ pain ( $0=$ 'no disability' and $100=$ 'worst disability') [35]. Adverse events that occurred throughout the study were recorded.

\section{Statistics}

Statistical analysis was performed using Excel (Microsoft, Redmond, WA). Means or medians (calculated to accommodate the small patient population and corresponding wide data variation with respect to the MEDD data) and SDs were calculated for continuous demographic and outcome data, and after absence of normal distribution was detected by the Kolmogorov-Smirnov test, means or medians were compared by the Wilcoxon test with $P<0.05$ indicating significant differences. Demographic categorical data (e.g., sex and subgroups defined as having previous back surgery) are expressed as the number of patients. Outcome categorical data (e.g., subgroups defined by treatment success) are reported as percentages.

\section{RESULTS}

\section{Demographics}

Twenty-seven (27/31, 87.1\%) patients had been chronically taking opioids (tapentadol $=15 / 27$ patients [55.6\%], oxycodone $/$ naloxone $=10 / 27[37.0 \%]$, codeine $=1 / 27[3.7 \%]$, and transdermal fentanyl $=1 / 27$ [3.7\%]) when the CRF denervations were performed. Table 1 shows the demographic profile of the study population. The majority $(85 \%)$ of those studied were females, the mean body mass index was slightly in the 'overweight' range [36], 15\% of the group had had previous back surgery, and the mean duration of pain was between 1 and 2 years.

Table 1. Demographics of Study Population

\begin{tabular}{lc}
\hline \multicolumn{1}{c}{ Variable } & Value \\
\hline Age $(\mathrm{yr})$ & $65.8 \pm 12.8$ \\
Sex $(\mathrm{M} / \mathrm{F})$ & $4 / 23$ \\
Body mass index $\left(\mathrm{kg} / \mathrm{m}^{2}\right)$ & $25.2 \pm 4.6$ \\
Previous back surgery & 4 \\
Duration of pain $(\mathrm{yr})$ & $1.60 \pm 0.75$ \\
\hline
\end{tabular}

Values are presented as mean \pm standard deviation or number only. 


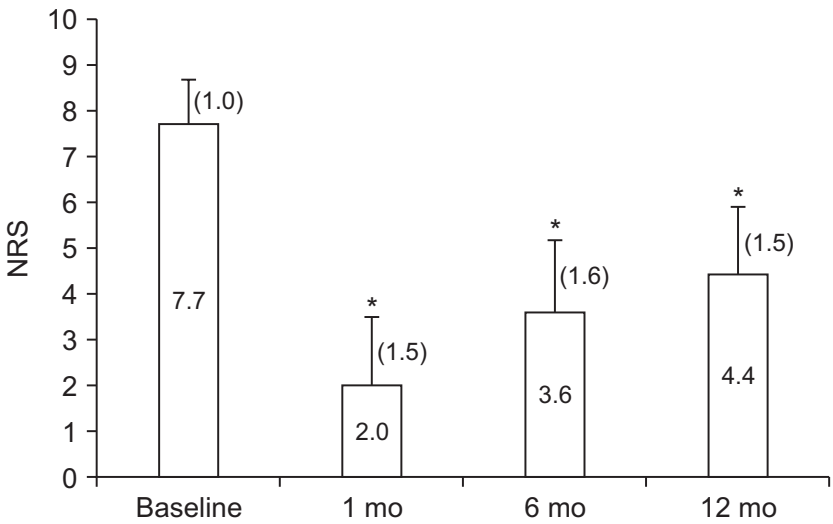

Fig. 1. Mean pain scores (NRS) experienced by the study group over time. Exact mean and standard deviation values are indicated within each bar and adjacent to each whisker, respectively. NRS: numeric rating scale. *Significantly different $(P<0.05)$ mean value compared to that at baseline.

\section{Pain}

Patients presented with severe pain (baseline NRS score $=7.7 \pm 1.0$; mean $\pm \mathrm{SD}$ ), which was significantly reduced up to 12 months following CRF denervation $(P<0.05$; Fig. 1). The mean \pm SD NRS score reductions at 1,6 , and 12 months were $5.6 \pm 1.6$, and $4.1 \pm 1.7$ and $3.2 \pm 1.6$, respectively. The CRF procedure was successful in $92.6 \%$ (25/27), $63.0 \%(17 / 27)$, and $44.4 \%(12 / 27)$ of the study group at 1 , 6 , and 12 months, respectively, post-CRF. None of the patients reported worsening pain at any of the follow-up visits, and 1 month following CRF, four patients experienced no pain from a baseline NRS of $8,8,7$, and 7 , respectively. For these four patients, at the 12-month follow-up, $62.5 \%$ $($ NRS score $=5), 50 \%($ NRS score $=4), 57.1 \%($ NRS score $=4)$, and $57.1 \%(\mathrm{NRS}$ score $=4$ ) of their original pain returned, respectively.

\section{Disability}

The severe disability in the study group at baseline (mean ODI score $=50.1 \pm 9.0$ ) was significantly reduced for up to 12 months after CRF denervation $(P<0.05, \mathrm{n}=27$; Fig. 2). Mean disability in the study group decreased by $30.7 \pm$ 12.6 points at 1 month, while at 6 and 12 months, by $24.6 \pm$ 12.1 and $20.2 \pm 11.6$ points, respectively. At 6 months, one patient reported $100 \%$ disability relief, of which $95 \%$ was sustained at 12 months.

\section{Opioid use}

\section{1) Entire study group}

Median MEDD was decreased significantly $(P<0.05, \mathrm{n}=$

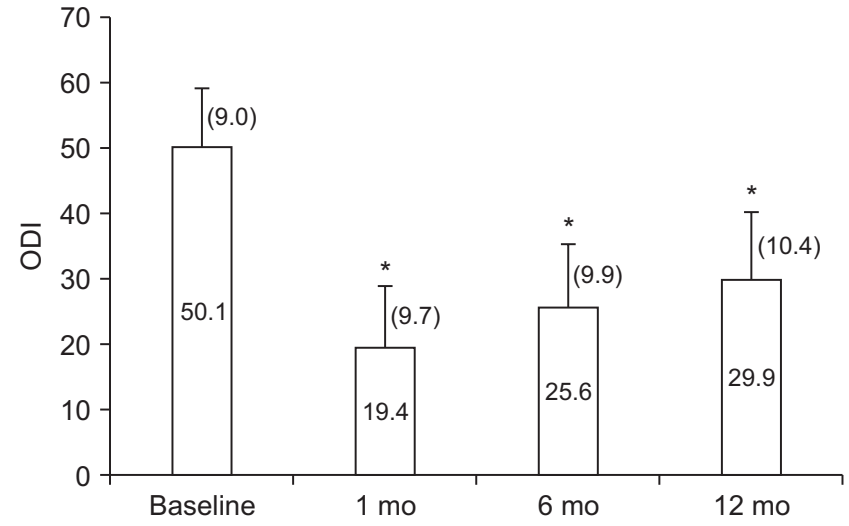

Fig. 2. Mean disability scores (ODI) experienced by the study group over time. Exact mean and standard deviation values are indicated within each bar and adjacent to each whisker, respectively. ODI: Oswestry disability index. *Significantly different $(P<0.05)$ mean value compared to that at baseline.

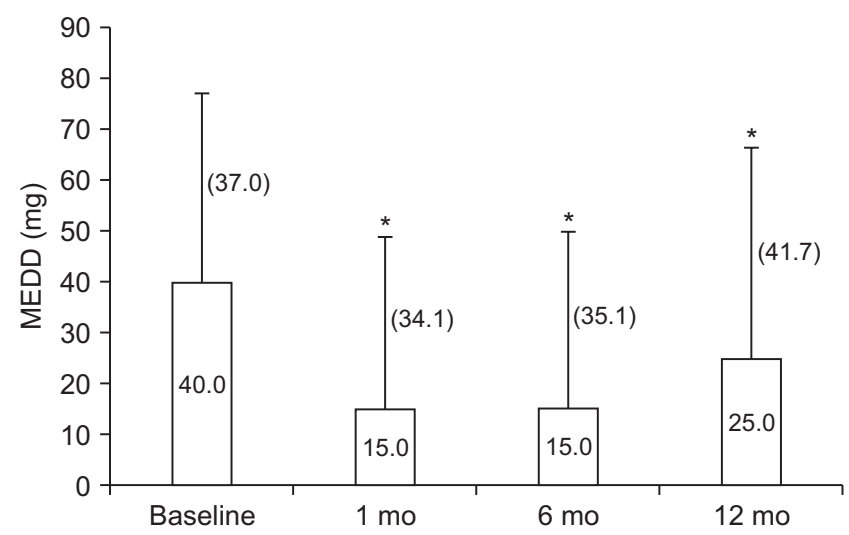

Fig. 3. Mean MEDD used by the study group over time. Exact mean and standard deviation values are indicated within each bar and adjacent to each whisker, respectively. MEDD: morphine equivalent daily dose. *Significantly different $(P<0.05)$ median value compared to that at baseline.

27) at each follow-up compared to baseline (Fig. 3). At 1, 6 , and 12 months following treatment, $29.6 \%(8 / 27)$, and $40.7 \%(11 / 27)$ and $25.9 \%(7 / 27)$ of the study group were not taking opioids, respectively. Five patients (18.5\%) did not take opioids at all during the follow-up period. But there were another five patients, who did not use opioids at one and/or six months, then returned to use them at 12 months. The dose of the opioids that these patients returned to using was as follows: tapentadol 50\% (2 patients), tapentadol 37.5\% (1 patient), tapentadol 25\% (1 patient), and oxycodone/naloxone $33.3 \%$ of their baseline dose. Two patients (7.4\%) who used opioids (tapentadol and oxycodone/naloxone) at 1 month did not use them at 6 and 12 months. 
A

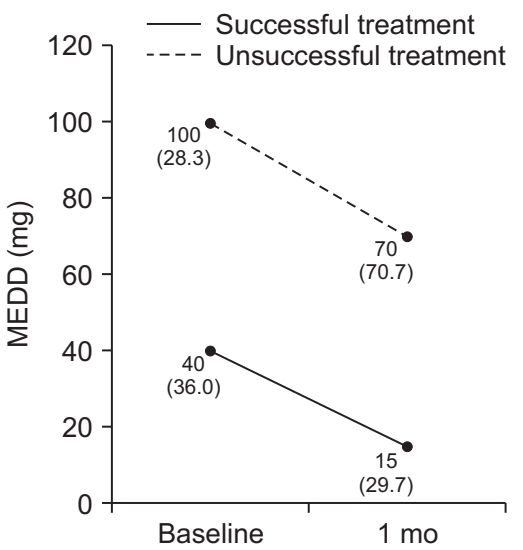

B

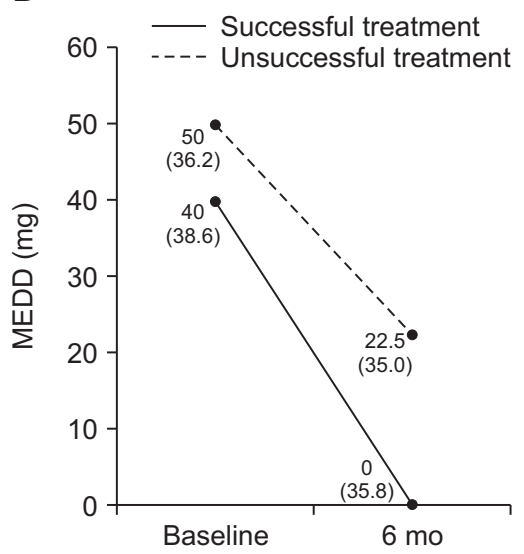

C

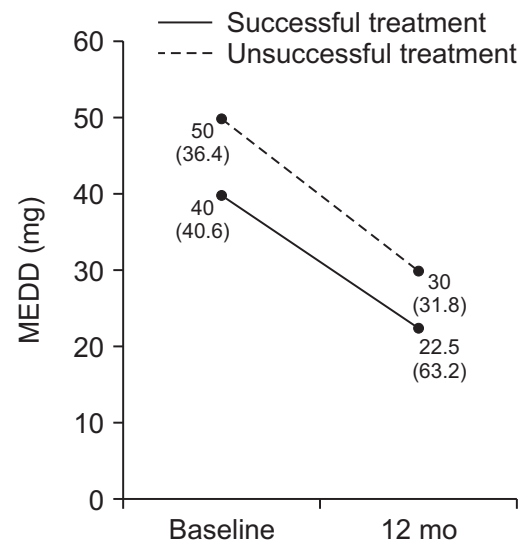

Fig. 4. Median MEDD of patients ( $n$ ) who had successful or unsuccessful treatments at each follow-up visit. Exact median and standard deviation values are indicated without and within parentheses, respectively. MEDD: morphine equivalent daily dose.

2) Successful vs. unsuccessful treatments

Fig. 4 describes the mean opioid consumption in patients from baseline to different follow-ups, dividing the population between patients who had a successful treatment (more than 50\% pain relief) and those who didn't experience such a reduction in pain score. Interestingly, the MEDD was reduced at 1 month (Fig. 4A; successful treatments: $\mathrm{n}=25$, unsuccessful: $\mathrm{n}=2$ ), 6 months (Fig. 4B; successful: $n=17$, unsuccessful: $n=10$ ), and 12 months (Fig. 4C; successful: $\mathrm{n}=12$, unsuccessful: $\mathrm{n}=15$ ) post-CRF denervation, not only for patients who had successful CRF denervation treatments, but also for those who had unsuccessful treatments. Moreover, at each follow-up visit, the extent of MEDD declines was similar for patients who had these respective outcomes.

Further analyses demonstrated that, at 12 months, the study population experienced changes in the MEDD defined as 'more' $(\mathrm{n}=2)$, 'no change' $(\mathrm{n}=4)$, 'reduced $\leq 50 \%$ ' $(\mathrm{n}=4)$, 'reduced $\geq 50 \%$ ' $(\mathrm{n}=10)$, or 'eliminated' $(\mathrm{n}=7)$, and interestingly reveal that, in most cases, equivalent or nearly equivalent fractions of patients who had successful or unsuccessful CRF denervation experienced each of these MEDD modifications (Fig. 5).

\section{Adverse events}

Two patients $(7.4 \%$ [2/27]) developed neuritis during the first week following the CRF denervation procedure with severe burning pain radiating down their leg. These patients were managed with a short course of oral steroid (prednisone, $25 \mathrm{mg} /$ day for 5 days) with a complete resolution of their symptoms. Each of these patients reported treatment success (in regards to pain) and less disability at each follow-up visit compared to their respective baseline

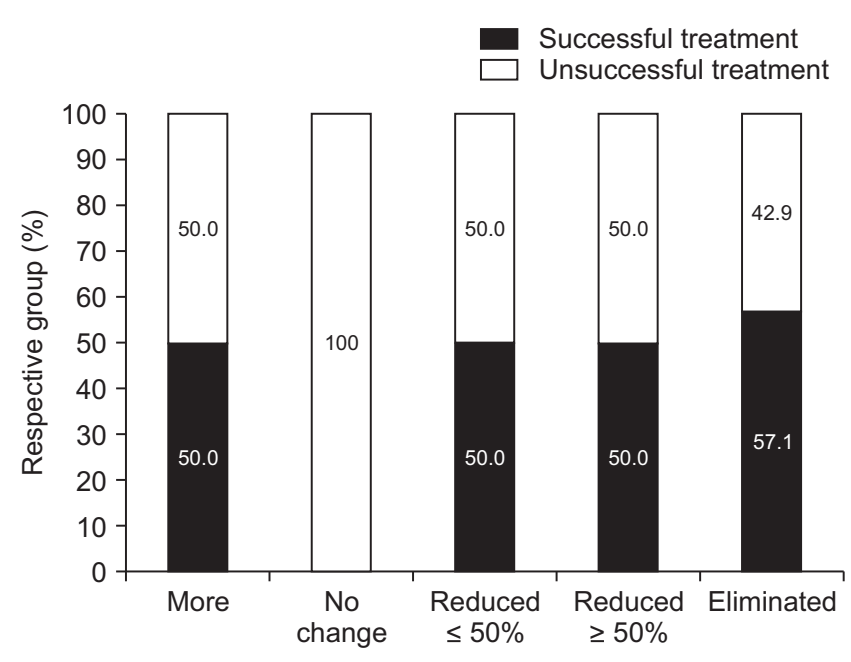

Status of patient's MEDD use 12 months post-CRF vs. baseline

Fig. 5. Changes at 12 months from baseline in MEDD for patients (n) who had successful or unsuccessful CRF denervation treatments. Exact percentage values are indicated within each bar. MEDD: morphine equivalent daily dose, CRF: cooled radiofrequency.

values for these outcomes.

\section{DISCUSSION}

CRF denervation of the SIJ significantly decreased SIJderived LBP and its associated disability at each followup visit up to 12 months. In addition, mean opioid use in the entire study group was significantly reduced from baseline at each follow-up visit. Reductions in opioid use were not observed selectively in patients who had successful treatments, as those who had unsuccessful treatments also reported less opioid use at each time-point compared to when the study began. By 12 months post-CRF denerva- 
tion, alterations in opioid use were, in most cases, evenly distributed among patients who experienced successful and unsuccessful treatments. Two instances of neuritis, a minor adverse event, occurred following CRF denervation.

While other investigators have also analyzed the influence of CRF denervation in the SIJ on opioid use $[19,20$, $22,23]$, this current report uniquely evaluated differential opioid use among patients who had successful or unsuccessful CRF denervation treatments, as determined by NRS score results. As expected, those who experienced the former outcome reduced their opioid intake. Remarkably, those who did not have a successful treatment also reduced their opioid consumption, and as demonstrated in Figs. 4, 5, to a similar extent as those in which CRF denervation was successful. This revelation may be due to the subjective nature of the pain scale, and suggests that monitored opioid use may serve as a useful surrogate to measure pain in studies of this kind and others that examine the relationship between opioid use and analgesic interventions. Randomized controlled studies are needed to further investigate the observations made in this report regarding opioid use among those who received successful and unsuccessful CRF denervation treatment of the SIJ.

Conservative therapeutic options such as IAS injections, NSAIDs, physical therapy, and opioids are commonly used to manage chronic LBP emanating from the SIJ region. These therapies are fraught with performance limitations, $[3-7,9]$ and may promote adverse events for patients $[6,9]$. Surgical fusion is highly invasive, may not be efficacious [8], and can be accompanied by complications such as infection [37-39], non-union [38-41], further surgery (hardware removal, scar tissue excision, second fusion) [38,40], and intraoperative fracture [40]. Furthermore, in their systematic review that indirectly compared surgical fusion (6 studies) to RF-mediated denervation (5 studies) for treating SIJ-derived LBP, Ashman et al. [42] found that each technique can reduce such pain, but fusion had a higher complication rate, with infection being uniquely included among the adverse events reported for this intervention (infections-excluded complication rates: fusion, 13.7\% [95 patients]; denervation, $7.3 \%$ [68 patients]). Taken together, clinical evidence suggests that non-invasive conservative therapies have limited efficacy, while at the other intervention extreme, invasive surgical fusion may be effective at the expense of an intolerable risk-to-benefit profile. The latter could exclude some patients, especially those who have comorbidities or are elderly, from surgical fusion. Thus, RF-facilitated denervation for SIJ-derived LBP may be a sensible intermediate therapy for patients.

Both conventional and cooled RF denervation options are available to treat SIJ-derived LBP. Technical and clinical findings infer an advantage to CRF compared to con- ventional RF for this ailment. The cooled probe tip of the CRF device permits a relatively larger lesion to be created compared to that of conventional $\mathrm{RF}$, as demonstrated on the canine heart [43]. This comparative advantage of CRF makes it more likely that this denervation technique can ablate the variable nerve courses assumed by nociceptive nerves in the SIJ [44,45]. We provided evidence to support such the favorability of CRF versus conventional RF when we directly compared two RF devices specifically designed to treat SIJ-derived LBP, SInergy ${ }^{\circledR}$ (Avanos Medical Inc., Alpharetta, GA) and Simplicity III ${ }^{\circledR}$ (NeuroTherm Inc., Wilmington, MA) [24]. In this retrospective analysis, pain relief and functional improvements were significantly greater up to 12 months for patients treated with SInergy $(\mathrm{n}=22)$ than with Simplicity III $(\mathrm{n}=21)$. Extending these findings to those in this current report suggests that CRF denervation provides patients with longer relief from use of opioids than conventional RF as an analgesic strategy for SIJ-derived LBP.

It is an important clinical goal to decrease or remove use of opioids for those afflicted with chronic SIJ-derived LBP. Generally speaking, there is an increasing concern that individuals who use opioids for chronic pain are at risk of their misuse, addiction, and death [13-15]. Deyo et al. [46] reviewed the use of opioids specifically for LBP. These authors reported that opioids have short-term (e.g., $<4$ mo) pain relief effects, possibly due to drug tolerance and subsequent hyperalgesia, and associations with poor functioning and work disability. Short-term complications include constipation, nausea, sedation, and increased risk of falls and fractures, while long-term adversities include depression and sexual dysfunction. A systematic review conducted by Chaparro et al. [47] demonstrated no advantage of opioids compared to NSAIDs or antidepressants with respect to pain and function for those who suffer from chronic LBP. A single CRF denervation of the SIJ can provide analgesia for up to 12 months and may have a more benign adverse event profile than opioid use over time [1024]. In addition, opioid use may portend less than optimal effectiveness for RF denervation of the SIJ [21]. The results of this present report suggest that CRF denervation would reduce or eliminate opioid use in patients with SIJ-derived LBP, regardless of pain relief outcome, thereby mitigating or obviating opioid side-effects. In addition, CRF denervation may provide more durable analgesia than opioid use for such patients.

This was not a prospective randomized controlled clinical trial. This examination included a relatively small population pool, with considerable variation in the MEDD outcome. Despite such limitations, the effect of CRF denervation on opioid consumption was significant up to 12 months. Without a control group in the study, patients may 
have artificially made their outcome tool responses to CRF denervation more positive than if a placebo treatment was also included in the study. Given the strong interest among healthcare workers and patients to reduce opioid use for chronic LBP, the focus of this study on that outcome is clinically-relevant. Adding to such relevance would be a direct comparison between CRF and conventional RF denervation to understand more clearly which may more effectively reduce opioid use among patients with SIJ-derived chronic LBP.

Statistically-significant analgesia and disability relief were manifested by CRF denervation in patients afflicted with SIJ-derived LBP for up to 12 months following the intervention. Moreover, opioid use was significantly reduced at each time-point following denervation for up to 12 months, and patients who reported successful or unsuccessful CRF denervation treatments reduced their use of opioids, and to similar extents.

This study provides further evidence that CRF denervation of the nociceptive nerves of the SIJ can safely provide meaningful pain and disability relief coupled with significantly less dependence on opioids. The latter benefit of CRF denervation may facilitate a means for patients who suffer from SIJ-derived LBP to escape use of opioids and the side-effects that can accompany their consumption. Future randomized controlled studies may provide further evidence that CRF denervation can reduce or eliminate opioid use in patients with SIJ-derived LBP, and buttress the notion suggested in this report that measuring opioid use may be a purposeful surrogate indicator of pain status.

\section{CONFLICT OF INTEREST}

Dr. Andrea Tinnirello received payments from Avanos Medical Inc. for participating as an instructor in cadaver workshops on cooled radiofrequency during 2018 and 2019.

\section{FUNDING}

No funding to declare.

\section{ORCID}

Andrea Tinnirello, https://orcid.org/0000-0003-2217-7942

\section{REFERENCES}

1. Cohen SP. Sacroiliac joint pain: a comprehensive review of anatomy, diagnosis, and treatment. Anesth Analg 2005; 101: 1440-53.

2. Dreyfuss P, Dreyer SJ, Cole A, Mayo K. Sacroiliac joint pain. J Am Acad Orthop Surg 2004; 12: 255-65.

3. Hansen H, Manchikanti L, Simopoulos TT, Christo PJ, Gupta S, Smith HS, et al. A systematic evaluation of the therapeutic effectiveness of sacroiliac joint interventions. Pain Physician 2012; 15: E247-78.

4. Simopoulos TT, Manchikanti L, Gupta S, Aydin SM, Kim CH, Solanki D, et al. Systematic review of the diagnostic accuracy and therapeutic effectiveness of sacroiliac joint interventions. Pain Physician 2015; 18: E713-56.

5. Lee JD, Lee DW, Jeong CW, Lee HG, Yoon MH, Kim WM. Effects of intraarticular prolotherapy on sacroiliac joint pain. Korean J Pain 2009; 22: 229-33.

6. Kuijpers T, van Middelkoop M, Rubinstein SM, Ostelo R, Verhagen A, Koes BW, et al. A systematic review on the effectiveness of pharmacological interventions for chronic nonspecific low-back pain. Eur Spine J 2011; 20: 40-50.

7. Garcia AN, Costa LDCM, Hancock MJ, Souza FS, Gomes GVFO, Almeida MO, et al. McKenzie method of mechanical diagnosis and therapy was slightly more effective than placebo for pain, but not for disability, in patients with chronic non-specific low back pain: a randomised placebo controlled trial with short and longer term follow-up. Br J Sports Med 2018; 52: 594-600.

8. Spiker WR, Lawrence BD, Raich AL, Skelly AC, Brodke DS. Surgical versus injection treatment for injection-confirmed chronic sacroiliac joint pain. Evid Based Spine Care J 2012; 3: 41-53.

9. Trang T, Al-Hasani R, Salvemini D, Salter MW, Gutstein H, Cahill CM. Pain and poppies: the good, the bad, and the ugly of opioid analgesics. J Neurosci 2015; 35: 13879-88.

10. National Institute on Drug Abuse. Opioid overdose crisis [Internet]. Bethesda (MD): National Institute on Drug Abuse; 2019. Available at: https://www.drugabuse.gov/drugs-abuse/ opioids/opioid-overdose-crisis.

11. Morone NE, Weiner DK. Pain as the fifth vital sign: exposing the vital need for pain education. Clin Ther 2013; 35: 1728-32.

12. Van Zee A. The promotion and marketing of oxycontin: commercial triumph, public health tragedy. Am J Public Health 2009; 99: 221-7.

13. Rudd RA, Seth P, David F, Scholl L. Increases in drug and opioid-involved overdose deaths - United States, 2010-2015. MMWR Morb Mortal Wkly Rep 2016; 65: 1445-52.

14. Florence CS, Zhou C, Luo F, Xu L. The economic burden of prescription opioid overdose, abuse, and dependence in the United States, 2013. Med Care 2016; 54: 901-6.

15. Vowles KE, McEntee ML, Julnes PS, Frohe T, Ney JP, van der 
Goes DN. Rates of opioid misuse, abuse, and addiction in chronic pain: a systematic review and data synthesis. Pain 2015; 156: 569-76.

16. Muhuri PK, Gfroerer JC, Davies MC. Associations of nonmedical pain reliever use and initiation of heroin use in the United States. CBHSQ Data Rev 2013; 8: 1-17.

17. Cicero TJ, Ellis MS, Surratt HL, Kurtz SP. The changing face of heroin use in the United States: a retrospective analysis of the past 50 years. JAMA Psychiatry 2014; 71: 821-6.

18. Carlson RG, Nahhas RW, Martins SS, Daniulaityte R. Predictors of transition to heroin use among initially non-opioid dependent illicit pharmaceutical opioid users: a natural history study. Drug Alcohol Depend 2016; 160: 127-34.

19. Ramasubba C, Cohen SP. Cooled sacroiliac radiofrequency denervation for the treatment of pain secondary to tumor infiltration: a case-based focused literature review. Pain Physician 2013; 16: 1-8.

20. Kapural L, Nageeb F, Kapural M, Cata JP, Narouze S, Mekhail $\mathrm{N}$. Cooled radiofrequency system for the treatment of chronic pain from sacroiliitis: the first case-series. Pain Pract 2008; 8: 348-54.

21. Cohen SP, Strassels SA, Kurihara C, Crooks MT, Erdek MA, Forsythe A, et al. Outcome predictors for sacroiliac joint (lateral branch) radiofrequency denervation. Reg Anesth Pain Med 2009; 34: 206-14.

22. Stelzer W, Aiglesberger M, Stelzer D, Stelzer V. Use of cooled radiofrequency lateral branch neurotomy for the treatment of sacroiliac joint-mediated low back pain: a large case series. Pain Med 2013; 14: 29-35.

23. Stelzer W, Stelzer V, Stelzer D, Braune M, Duller C. Influence of BMI, gender, and sports on pain decrease and medication usage after facet-medial branch neurotomy or SI joint lateral branch cooled RF-neurotomy in case of low back pain: original research in the Austrian population. J Pain Res 2017; 10: 183-90.

24. Tinnirello A, Barbieri S, Todeschini M, Marchesini M. Conventional (Simplicity III) and cooled (SInergy) radiofrequency for sacroiliac joint denervation: one-year retrospective study comparing two devices. Pain Med 2017; 18: 1731-44.

25. Cohen SP, Chen Y, Neufeld NJ. Sacroiliac joint pain: a comprehensive review of epidemiology, diagnosis and treatment. Expert Rev Neurother 2013; 13: 99-116.

26. Laslett M, Aprill CN, McDonald B, Young SB. Diagnosis of sacroiliac joint pain: validity of individual provocation tests and composites of tests. Man Ther 2005; 10: 207-18.

27. Szadek KM, van der Wurff P, van Tulder MW, Zuurmond WW, Perez RS. Diagnostic validity of criteria for sacroiliac joint pain: a systematic review. J Pain 2009; 10: 354-68.

28. Hegarty D. Clinical outcome following radiofrequency denervation for refractory sacroiliac joint dysfunction using the Simplicity III probe: a 12-month retrospective evaluation. Pain Physician 2016; 19: E129-35.
29. Bellini M, Barbieri M. Single strip lesions radiofrequency denervation for treatment of sacroiliac joint pain: two years' results. Anaesthesiol Intensive Ther 2016; 48: 19-22.

30. Ho KY, Hadi MA, Pasutharnchat K, Tan KH. Cooled radiofrequency denervation for treatment of sacroiliac joint pain: two-year results from 20 cases. J Pain Res 2013; 6: 505-11.

31. Cohen SP, Hurley RW, Buckenmaier CC 3rd, Kurihara C, Morlando B, Dragovich A. Randomized placebo-controlled study evaluating lateral branch radiofrequency denervation for sacroiliac joint pain. Anesthesiology 2008; 109: 279-88.

32. Franklin G, Sabel J, Jones CM, Mai J, Baumgartner C, BantaGreen CJ, et al. A comprehensive approach to address the prescription opioid epidemic in Washington state: milestones and lessons learned. Am J Public Health 2015; 105: 463-9.

33. Farrar JT, Young JP Jr, LaMoreaux L, Werth JL, Poole RM. Clinical importance of changes in chronic pain intensity measured on an 11-point numerical pain rating scale. Pain 2001; 94: 149-58.

34. Dworkin RH, Turk DC, Wyrwich KW, Beaton D, Cleeland CS, Farrar JT, et al. Interpreting the clinical importance of treatment outcomes in chronic pain clinical trials: IMMPACT recommendations. J Pain 2008; 9: 105-21.

35. Fairbank JC, Pynsent PB. The Oswestry disability index. Spine (Phila Pa 1976) 2000; 25: 2940-52.

36. Nuttall FQ. Body mass index: obesity, BMI, and health: a critical review. Nutr Today 2015; 50: 117-28.

37. Al-Khayer A, Hegarty J, Hahn D, Grevitt MP. Percutaneous sacroiliac joint arthrodesis: a novel technique. J Spinal Disord Tech 2008; 21: 359-63.

38. Buchowski JM, Kebaish KM, Sinkov V, Cohen DB, Sieber AN, Kostuik JP. Functional and radiographic outcome of sacroiliac arthrodesis for the disorders of the sacroiliac joint. Spine J 2005; 5: 520-8.

39. Waisbrod H, Krainick JU, Gerbershagen HU. Sacroiliac joint arthrodesis for chronic lower back pain. Arch Orthop Trauma Surg 1987; 106: 238-40.

40. Schütz U, Grob D. Poor outcome following bilateral sacroiliac joint fusion for degenerative sacroiliac joint syndrome. Acta Orthop Belg 2006; 72: 296-308.

41. Wise CL, Dall BE. Minimally invasive sacroiliac arthrodesis: outcomes of a new technique. J Spinal Disord Tech 2008; 21: 579-84.

42. Ashman B, Norvell DC, Hermsmeyer JT. Chronic sacroiliac joint pain: fusion versus denervation as treatment options. Evid Based Spine Care J 2010; 1: 35-44.

43. Watanabe I, Masaki R, Min N, Oshikawa N, Okubo K, Sugimura $\mathrm{H}$, et al. Cooled-tip ablation results in increased radiofrequency power delivery and lesion size in the canine heart: importance of catheter-tip temperature monitoring for prevention of popping and impedance rise. J Interv Card Electrophysiol 2002; 6: 9-16. 
44. Roberts SL, Burnham RS, Ravichandiran K, Agur AM, Loh EY. Cadaveric study of sacroiliac joint innervation: implications for diagnostic blocks and radiofrequency ablation. Reg Anesth Pain Med 2014; 39: 456-64.

45. Cox RC, Fortin JD. The anatomy of the lateral branches of the sacral dorsal rami: implications for radiofrequency ablation. Pain Physician 2014; 17: 459-64.
46. Deyo RA, Von Korff M, Duhrkoop D. Opioids for low back pain. BMJ 2015; 350: g6380.

47. Chaparro LE, Furlan AD, Deshpande A, Mailis-Gagnon A, Atlas S, Turk DC. Opioids compared to placebo or other treatments for chronic low-back pain. Cochrane Database Syst Rev 2013; (8): CD004959. 